OPEN ACCESS

Edited by:

Erika Kothe,

Friedrich-Schiller-Universität Jena,

Germany

Reviewed by:

Christopher Rensing,

Fujian Agriculture and Forestry

University, China

Michael Bölker,

Philipps University of Marburg,

Germany

*Correspondence:

Pavel Kotrba

pavel.kotrba@vscht.cz

Specialty section:

This article was submitted to Fungi and Their Interactions,

a section of the journal

Frontiers in Microbiology

Received: 28 September 2017

Accepted: 03 April 2018

Published: 23 April 2018

Citation:

Beneš V, Leonhardt T, Sácký J and Kotrba $P$ (2018) Two $P_{1 \mathrm{~B}-1}$-ATPases of Amanita strobiliformis With Distinct

Properties in Cu/Ag Transport.

Front. Microbiol. 9:747.

doi: 10.3389/fmicb.2018.00747

\section{Two $\mathrm{P}_{1 \mathrm{~B}-1}$-ATPases of Amanita strobiliformis With Distinct Properties in Cu/Ag Transport}

\author{
Vojtěch Beneš, Tereza Leonhardt, Jan Sácký and Pavel Kotrba* \\ Department of Biochemistry and Microbiology, University of Chemistry and Technology Prague, Prague, Czechia
}

As we have shown previously, the $\mathrm{Cu}$ and $\mathrm{Ag}$ concentrations in the sporocarps of Ag-hyperaccumulating Amanita strobiliformis are correlated, and both metals share the same uptake system and are sequestered by the same metallothioneins intracellularly. To further improve our knowledge of the $\mathrm{Cu}$ and $\mathrm{Ag}$ handling in A. strobiliformis cells, we searched its transcriptome for the $\mathrm{P}_{1 \mathrm{~B}-1}$-ATPases, recognizing $\mathrm{Cu}^{+}$and $\mathrm{Ag}^{+}$for transport. We identified transcripts encoding 1097-amino acid (AA) AsCRD1 and 978AA AsCCC2, which were further subjected to functional studies in metal sensitive Saccharomyces cerevisiae. The expression of AsCRD1 conferred highly increased $\mathrm{Cu}$ and Ag tolerance to metal sensitive yeasts in which the functional AsCRD1:GFP (green fluorescent protein) fusion localized exclusively to the tonoplast, indicating that the AsCRD1-mediated $\mathrm{Cu}$ and $\mathrm{Ag}$ tolerance was a result of vacuolar sequestration of the metals. Increased accumulation of AsCRD1 transcripts observed in A. strobiliformis mycelium upon the treatments with $\mathrm{Cu}$ and $\mathrm{Ag}$ (8.7- and 4.5-fold in the presence of $5 \mu \mathrm{M}$ metal, respectively) supported the notion that AsCRD1 can be involved in protection of the $A$. strobiliformis cells against the toxicity of both metals. Neither $\mathrm{Cu}$ nor $\mathrm{Ag}$ affected the levels of AsCCC2 transcripts. Heterologous expression of AsCCC2 in mutant yeasts did not contribute to Cu tolerance, but complemented the mutant genotype of the S. cerevisiae $\operatorname{ccc} 2 \Delta$ strain. Consistent with the role of the yeast $\mathrm{Ccc} 2$ in the trafficking of $\mathrm{Cu}$ from cytoplasm to nascent proteins via post-Golgi, the GFP fluorescence in AsCCC2-expressing ccc2 $\Delta$ yeasts localized among Golgilike punctate foci within the cells. The AsCRD1- and AsCCC2-associated phenotypes were lost in yeasts expressing mutant transporter variants in which a conserved phosphorylation/dephosphorylation site was altered. Altogether, the data support the roles of AsCRD1 and AsCCC2 as genuine $\mathrm{P}_{1 \mathrm{~B}-1}$-ATPases, and indicate their important functions in the removal of toxic excess of $\mathrm{Cu}$ and $\mathrm{Ag}$ from the cytoplasm and charging the endomembrane system with $\mathrm{Cu}$, respectively.

Keywords: ectomycorrhizal fungi, $\mathbf{P}_{1}$-type ATPase, copper transporter, silver transporter, metal homeostasis, Amanita strobiliformis

\section{INTRODUCTION}

Studies have revealed that ectomycorrhizal (EM) fungi effectively mobilize heavy metals from soils and minerals (Gadd et al., 2012) and that ectomycorrhizae improve plant fitness in metal polluted environments also because metal tolerant mycobionts function as a barrier for the entry of metals into plant tissues (Colpaert et al., 2011; Reddy et al., 2016). High concentrations of heavy metals and 
metalloids accumulated in the sporocarps further support the notion that EM fungi substantially contribute to the environmental cycling of these elements, including $\mathrm{Cu}$ and Ag (Falandysz and Borovička, 2013). It is noteworthy that studies indicate that macrofungi could be considered the most effective Ag accumulators among eukaryotes with two known outstanding EM species, Amanita strobiliformis and Amanita solitaria (Borovička et al., 2007, 2010). The concentrations of Ag in their sporocarps collected from unpolluted sites range from 200 to $1200 \mathrm{mg} \mathrm{kg}^{-1}$. We have documented that the intracellular detoxification of $\mathrm{Cu}$ and $\mathrm{Ag}$ in A. strobiliformis largely relies upon binding with cysteinyl-rich, cytosolic metallothionein (MT) peptides, AsMT1a, 1b, and 1c (Osobová et al., 2011; Beneš et al., 2016; Hložková et al., 2016); and that two A. strobiliformis transporters of the copper transporter family (CTR; specifically AsCTR2 and AsCTR3) can recognize not only $\mathrm{Cu}$, but also Ag for uptake (Beneš et al., 2016).

Studies in eukaryotes have revealed that while CTRs transport $\mathrm{Cu}$ ions into the cytoplasm, the members of $\mathrm{P}_{1 \mathrm{~B}-1}$ subgroup of $\mathrm{P}_{1 \mathrm{~B}}$-type ATPases (also called heavy metal ATPases, HMA) contribute to the homeostasis and redistribution of essential $\mathrm{Cu}$ by exporting the metal ion from the cytoplasm into the subcellular compartments or out of the cell (Nevitt et al., 2012; Bashir et al., 2016). The homology of $\mathrm{P}_{1 \mathrm{~B}}$-ATPases and their characteristic sequence features suggest a division into seven subgroups (Smith et al., 2014). While the roles of the members of the $\mathrm{P}_{1 \mathrm{~B}-5}$ to $\mathrm{P}_{1 \mathrm{~B}-7}$ subgroups (predicted so far only in prokaryotes) remain elusive, the transporters belonging to $\mathrm{P}_{1 \mathrm{~B}-1}, \mathrm{P}_{1 \mathrm{~B}-2}$, prokaryote $\mathrm{P}_{1 \mathrm{~B}-3}$, and $\mathrm{P}_{1 \mathrm{~B}-4}$ subgroups are known for distinct preferences for their substrate heavy metal ion(s). The transporters highly specific for monovalent $\mathrm{Cu}$ ions (the dominant intracellular $\mathrm{Cu}$ species in eukaryotes; Nevitt et al., 2012) comprise $\mathrm{P}_{1 \mathrm{~B}-1}$-subgroup, while $\mathrm{P}_{1 \mathrm{~B}-2}, \mathrm{P}_{1 \mathrm{~B}-3}$, and $\mathrm{P}_{1 \mathrm{~B}-4}$ transport $\mathrm{Cd}^{2+} / \mathrm{Zn}^{2+} / \mathrm{Pb}^{2+}, \mathrm{Cu}^{+} / \mathrm{Cu}^{2+}$, and $\mathrm{Co}^{2+}$, respectively.

The intracellular handling of $\mathrm{Cu}$ involves in Saccharomyces cerevisiae Ccc2 protein (Bleackley and MacGillivray, 2011), and in mammals the Menkes protein ATP7A and Wilson protein ATP7B (La Fontaine and Mercer, 2007; Nevitt et al., 2012). These $\mathrm{P}_{1 \mathrm{~B}-1}$-ATPases are responsible for the transport of the physiological $\mathrm{Cu}$ into the post-Golgi. Unlike with $\mathrm{Ccc} 2$ in $S$. cerevisiae, the $\mathrm{Cu}$ overload in mammalian cells triggers trafficking of ATP7A to the plasma membrane and ATP7B to the excretory vesicles, and both transporters then facilitate the efflux of the excess metal to rescue the cell from $\mathrm{Cu}$ toxicity. Similar trafficking [from the endoplasmic reticulum (ER) to the plasma membrane] stimulated by $\mathrm{Cu}$ overload has been documented in Arabidopsis thaliana for its AtHMA5 and heterologously expressed SvHMA5I from Silene vulgaris (Li et al., 2017). It is noteworthy that several $\mathrm{P}_{1 \mathrm{~B}-1}$-ATPases have been shown to also recognize Ag for transport (Argüello et al., 2007; Smith et al., 2014; Migocka et al., 2015). Among fungi, the plasma membrane $\mathrm{Cu}^{+}$- and $\mathrm{Ag}^{+}$-efflux CaCRD1 of Candida albicans provides the primary source of cellular resistance against both metals (Riggle and Kumamoto, 2000; Weissman et al., 2000). Recently, the $\mathrm{P}_{1 \mathrm{~B}-1}$-ATPase CrpA that also localizes to the plasma membrane has been shown to confer substantial $\mathrm{Cu}$ - but not Ag-tolerance in filamentous fungus Aspergillus nidulans (Antsotegi-Uskola et al., 2017).

Since our previous studies revealed certain overlap in the cell biology of $\mathrm{Ag}$ and $\mathrm{Cu}$ in $\mathrm{A}$. strobiliformis, we investigated whether or not this species may employ $\mathrm{P}_{1 \mathrm{~B}-1}$-ATPases in the intracellular handling of both $\mathrm{Cu}$ and $\mathrm{Ag}$. We searched its transcriptome for the homologs of $\mathrm{P}_{1 \mathrm{~B}-1}$-ATPases and describe here the isolation and functional characterization of cDNA coding the $\mathrm{Cu}$ - and Ag-inducible AsCRD1 that can protect metal-sensitive yeasts against the toxicity of both metals. We also describe the second isolated $\mathrm{P}_{1 \mathrm{~B}-1}$-ATPase of $A$. strobiliformis, the homolog of yeast Ccc2 named AsCCC2. To our knowledge, these are the first $\mathrm{P}_{1 \mathrm{~B}-1}$-ATPases characterized in mycorrhizal fungi.

\section{MATERIALS AND METHODS}

\section{Amplification of AsCRD1 and AsCCC2 Genes and Sequence Analyses}

Partial sequences of AsCRD1 and AsCCC2 transcripts were obtained from tBLASTn analysis (Altschul et al., 1990) of the transcriptome of A. strobiliformis (Paulet ex Vittad.) isolate PRM 857486 (Hložková et al., 2016) by using characterized fungal

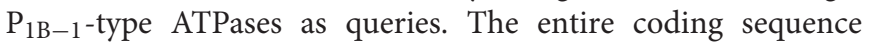
information was established by $5^{\prime}$ and $3^{\prime}$ RACE, using a SMARTer RACE cDNA Amplification Kit (Clontech Labs) with $1 \mu \mathrm{g}$ of total RNA to produce the population of the first cDNA strand; the Q5 High-Fidelity DNA polymerase (New England Biolabs) was used to obtain double-stranded cDNAs. The total RNA was isolated by using an RNeasy Plant Mini Kit and RNase free DNase set (Qiagen) from $50 \mathrm{mg}$ of freeze-dried tissue of the A. strobiliformis PRM 857486 sporocarp. Transcript-specific primers were 5rCRD1_R1 to $\mathrm{R} 5$ for AsCRD1 5' RACE, and 5rCRD2_R1 to R3 or 3rCRD2R1 and R2 for AsCCC2 $5^{\prime}$ or $3^{\prime}$ RACE, respectively (for primer sequences see Supplementary Table S1), and the amplicons were subjected to $3^{\prime}$-A tailing with GoTaq DNA polymerase (Promega). Genomic fragments harboring AsCRD1 and AsCCC2 genes were amplified from $200 \mathrm{ng}$ of chromosomal DNA template by PCR using Q5 DNA polymerase and pairs of gene-specific primers designed based on $5^{\prime}$ and $3^{\prime}$ untranslated regions of the corresponding cDNAs; the primers were CRD1_F/R for AsCRD1 and CRD2_F/R for AsCCC2 (Supplementary Table S1). The chromosomal DNA was isolated from $50 \mathrm{mg}$ of freeze-dried tissue of A. strobiliformis PRM 857486 by using a NucleoSpin Plant II Kit (Macherey-Nagel). The amplicons were inserted to a pGEM-T vector (Promega) and then amplified in E. coli $\mathrm{DH} 5 \alpha$ according to standard protocols. The recombinant DNAs were subjected to custom DNA sequencing on both strands with the vector-specific primers. The sequences of AsCRD1 and AsCCC2 cDNAs were deposited in GenBank under the accession numbers MF317930 and MF317931, respectively.

\section{Sequence Analyses}

The protein sequences deduced from the cDNAs were subjected to a transmembrane domain and signal peptide predictions 
in silico at the CCTOP web server (Dobson et al., 2015). The signal peptide prediction was also done by submitting the sequences to SignalP 4.1 server (Pettersen et al., 2004). The homology modeling of transporter 3D structure used the Phyre2 protein homology/analogy recognition engine (Kelley et al., 2015), the Modeller (Webb and Sali, 2014), and UCSF Chimera (Pettersen et al., 2004) programs. The closest AsCRD1 and AsCCC2 homologs among the RCSB Protein Data Bank (PDB) entries used for comparative modeling were 2EW9 (N-terminal domain of ATP7B, 23\% and $40 \%$ identity, respectively) and 3J09 ( $\mathrm{P}_{1 \mathrm{~B}-1}$-ATPase of Archaeoglobus fulgidus; $34 \%$ and $41 \%$ identity, respectively). A MEGA 6.0 package (Tamura et al., 2013) incorporating ClustalW (Thompson et al., 1994) was used to align AsCRD1, AsCCC2, and related amino acid (AA) sequences (retrieved from UniProtKB datase by using BLASTp) and construct the corresponding unrooted phylogenetic tree using the Neighborjoining method with Poisson correction model and 10,000 bootstrap replications.

\section{Functional Complementation in Yeasts}

The $S$. cerevisiae strains used in complementation assays were

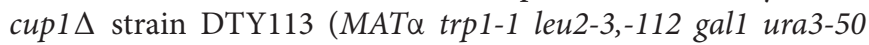
cup1 $\Delta 61$; Tamai et al., 1993) and the Euroscarf ${ }^{1}$ Y00569 (yap1 $\Delta$; YML007w::kanMX4) and Y03629 (ccc2 $\Delta$; YDR270w::kanMX4) mutant strains of BY4741 (MATa his $3 \Delta 1$ leu $2 \Delta 0$ met15 $\Delta 0$ ura3 $\Delta 0$ ). To constitutively express AsCRD1 and AsCCC2 in yeasts, the entire coding sequences produced by Q5 DNA polymerase from cDNA using primer pairs eifCRD1_F/R (AsCRD1) and eifCRD2_F/R (AsCCC2) were inserted into the HindIII-treated and EcoRI-treated yeast expression vector p416GPD (Mumberg et al., 1995), respectively, by using an In-Fusion HD Cloning Kit (Clontech Labs) according to manufacturer's instructions. Site-directed mutagenesis of AsCRD1 and AsCCC2 in p416GPD was performed by the inverse PCR method (Füzik et al., 2014) with Phusion HighFidelity DNA Polymerase (Thermo Scientific); the overlapping primers used were mCRD1_F plus mCRD1_R and mCRD2_F plus mCRD2_R, respectively. Primer sequences are listed in Supplementary Table S1. The yeasts transformed with p416GPD-based plasmids were routinely grown at $30^{\circ} \mathrm{C}$ on $U R A^{-}$selective SD medium containing (w/v) $0.7 \%$ yeast nitrogen base (Difco), $0.005 \%$ adenine hemisulfate, $2 \%$ glucose, and $0.003 \%$ of each of the essential amino acids (SigmaAldrich).

For complementation plate assays, the mid-log cultures of transformed $S$. cerevisiae were adjusted to an optical density at $590 \mathrm{~nm}\left(\mathrm{OD}_{590}\right)$ of 0.1 , and $5 \mu \mathrm{l}$ of serial dilutions were spotted on agar medium. The metal (added as $\mathrm{CuCl}_{2}$ or $\mathrm{AgNO}_{3}$ ) tolerance of cup $1 \Delta$ and yap $1 \Delta$ transformants was assayed on $\mathrm{SD}$ medium and non-fermentable YPEG medium [1\% (w/v) yeast extract, 2\% ([w/v) peptone, 2.5\% (v/v) ethanol and $2.5 \%(\mathrm{v} / \mathrm{v})$ glycerol], respectively. The growth tests of $\operatorname{ccc} 2 \Delta$ transformants used non-fermentable YPEG medium.

${ }^{1}$ http://web.uni-frankfurt.de/fb15/mikro/euroscarf/

\section{Fluorescence Microscopy of AsCRD1:GFP and AsCCC2:GFP-Expressing Yeasts}

To construct the translational AsCRD1:GFP and AsCCC2:GFP fusions, the coding sequences without the termination codons were amplified from cDNA by using primer pairs gifCRD1_F plus gifCRD2_R for AsCRD1 and gifCRD2_F plus gifCRD2_R for AsCCC2 (Supplementary Table S1). The amplicons were inserted into a BamHI-digested plasmid p416GFP. The plasmid p416GFP is a $416 \mathrm{GPD}$ derivative, harboring GFP from plasmid pEGFP-C1 (Clontech Labs) inserted as a BamHI/HindIII DNA fragment (Hložková et al., 2016). The cells of AsCRD1:GFPexpressing cup $1 \Delta$ and AsCCC2:GFP-expressing $c c c 2 \Delta$ yeasts were obtained from mid-log cultures grown in SD medium supplemented with $0.5 \mu \mathrm{g} \cdot \mathrm{ml}^{-1}$ DAPI (Invitrogen) when needed. Vacuoles were labeled at $30^{\circ} \mathrm{C}$ for $4 \mathrm{~h}$ in SD medium with $400 \mu \mathrm{g} \cdot \mathrm{ml}^{-1}$ of the tonoplast-specific FM4-64 dye (Molecular Probes). The fluorescence microscopy was performed by using a BioSystems Imaging station Cell^ ${ }^{\wedge}$ with a MT20 illumination and a DSU semiconfocal unit on a IX-81 microscope (Olympus BioSystems) equipped with the model C9100 EM-CCD camera (Hamamatsu Photonix). A GFP-deriving fluorescence was observed with the U-DM-DA-FI-Tx2 FITC filter (excitation band: 495/15 nm, emission band: 530/30 nm; Olympus) and nuclei stained with DAPI were visualized with the U-DM-DAFI-Tx2 DAPI filter (excitation band: $400 / 15 \mathrm{~nm}$, emission band: $460 / 20 \mathrm{~nm}$ ). Vacuoles were observed with the U-DM-Cy5 filter (excitation band: $590-650 \mathrm{~nm}$, emission band: 665-740 nm). The recorded black and white images were processed using the Image software ${ }^{2}$.

\section{Gene Expression Analysis in A. strobiliformis}

The mycelium isolate from the PRM 857486 pileus (Osobová et al., 2011) was grown at $25^{\circ} \mathrm{C}$ and routinely maintained on potato dextrose (PD) agar containing $4 \mathrm{~g} \cdot \mathrm{l}^{-1}$ potato extract (Sigma-Aldrich) and $10 \mathrm{~g} \cdot \mathrm{l}^{-1}$ glucose $(0.5 \times \mathrm{PD})$. The metal dose-dependent growth was observed with mycelia grown for 8 weeks on $0.5 \times \mathrm{PD}$ agar with $\mathrm{CuCl}_{2}$ or $\mathrm{AgNO}_{3}$ supplements. The expression of target genes was assessed in the mycelium propagated in liquid PD medium (basal $\mathrm{Cu}, \mathrm{Ag}$ and Cd concentrations below the atomic absorption spectrometry detection limit of $0.21,0.04$, and $0.09 \mu \mathrm{M}$, respectively) for 16 weeks and then subjected to metal (added as $\mathrm{CuCl}_{2}, \mathrm{AgNO}_{3}$, or $\mathrm{CdCl}_{2}$ ) exposures for $24 \mathrm{~h}$. The gene expression analysis was performed on independent biological samples from three replicate experiments in two technical replicates. The RNA extraction from freeze-dried mycelia and quantitative reversetranscribed PCR measurements including the quality/specificity controls were conducted essentially as described previously (Hložková et al., 2016). Briefly, the population of transcripts present in $1 \mu \mathrm{g}$ of total RNA was reverse transcribed in a $20 \mu \mathrm{l}$ reaction and $1.5 \mu \mathrm{l}$ of the resulting cDNA product was used in a $12 \mu \mathrm{l}$ quantitative PCR (qPCR) reaction for the measurements

\footnotetext{
${ }^{2}$ http://imagej.nih.gov/ij/
} 
with $0.35 \mu \mathrm{M}$ gene-specific primers (Supplementary Table S1). The measurements used a DyNAmo Flash SYBR Green 2Step qPCR Kit (Life Technologies) and a MiniOpticon Real Time PCR System (Bio-Rad). The primers were qF- plus qRCRD1 for AsCRD1, qF- plus qR-CRD2 for AsCRD1, and qFtub-b plus qRtub-b for $\beta$-tubulin AsTUB- $b$ gene (GenBank: JX463743), which was used for normalization of the qPCR data as internal reference, stably expressed under $\mathrm{Ag}$ and $\mathrm{Cu}$ exposures (Hložková et al., 2016). A Bio-Rad CFX Manager was used to calculate the baseline range and the experiment threshold cycle $\left(\mathrm{C}_{\mathrm{te}}\right)$ values recorded during the elongation period of the qPCR. The levels of gene transcription as relative to the controls (unexposed mycelium) were calculated by using the $2^{-\Delta \Delta \mathrm{Ct1}}$ method (Livak and Schmittgen, 2001), where $\mathrm{C}_{\mathrm{t} 1}=\mathrm{C}_{\mathrm{te}} \times[\log (1+E) / \log 2]$. The amplification efficiency values (E) were calculated using the equation $E=\left[10^{(-1 / \text { slope })}\right]-1$; the slopes were determined from the standard quantification curves obtained with serial dilutions of first strand cDNA templates. The obtained $E$ values for AsCRD1, AsCCC2 and AsTUBb genes were $102 \%$, $98 \%$, and $108 \%$, respectively.

\section{RESULTS}

\section{Identification and Sequence Analysis of AsCRD1 and AsCCC2}

To obtain information about the sequences coding for $\mathrm{P}_{1 \mathrm{~B}-1^{-}}$ATPases in A. strobiliformis, the sporocarp transcriptome of A. strobiliformis was screened by using tBLASTn search with known $\mathrm{P}_{1 \mathrm{~B}-1}$-ATPases as queries. The screening retrieved two partial transcript sequences: one 822 nucleotides long in which a termination codon was included (a part of mRNA named AsCRD1) and another 528 nucleotides long without a termination codon (a part of mRNA named AsCCC2). As the deduced protein fragments showed a substantial identity with the $\mathrm{C}$-terminal sequences of known $\mathrm{P}_{1 \mathrm{~B}-1}$-ATPases, the corresponding full-length coding sequences were established via the RACE method.

The predicted 1097-AA AsCRD1 and 978-AA AsCCC2 proteins showed the characteristic sequence features of $\mathrm{P}_{1 \mathrm{~B}-1^{-}}$ATPases described in other organisms (Argüello et al., 2007; Smith et al., 2014). These involve putative N-terminal Cu/Agbinding CxxC motifs (three in AsCRD1, two in AsCCC2) and two $\mathrm{P}_{1 \mathrm{~B}-1}$ subgroup signature sequences in predicted transmembrane domains (TMD), $\mathrm{Nx}_{6} \mathrm{YNx}_{4} \mathrm{P}$ ( $\mathrm{x}$ represents any $\mathrm{AA}$ residue), and $\mathrm{Px}_{6} \mathrm{MxxSS}_{5} \mathrm{~S}$, which are in $\mathrm{P}_{1 \mathrm{~B}-1}$-ATPases conserved in TMD7 and TMD8, respectively (Figure 1 and Supplementary Figure S1). Like other $\mathrm{P}_{1 \mathrm{~B}}$-type ATPases, AsCRD1 and AsCCC2 contained eight predicted TMDs with $\mathrm{CPCx}_{6} \mathrm{P}$ sequence in TMD6 and HP locus between TMD6 and TMD7. In addition, both predicted proteins possess features typical for all the members of the P-ATPase superfamily (Figure 1), particularly the DKTGTxT motif in the predicted large cytoplasmic loop with an aspartyl residue whose phosphorylation from ATP and dephosphorylation is prerequisite for active metal ion transport (Palmgren and Nissen, 2011). Despite the identified regions of conservancy at the protein level, the corresponding genes showed different structure and appeared dissimilar. The cDNA and genomic sequences of AsCRD1 and AsCCC2 were clearly distinct, with coding sequences interrupted with nine and three introns, respectively (Figure 1).

The comparison of the predicted AsCRD1 and AsCCC2 proteins revealed that along the sequence, they show lower identity and similarity with each other $(25 \%$ and $38 \%$, respectively) than they individually showed to $\mathrm{P}_{1 \mathrm{~B}-1}$-ATPases characterized from other species. Predicted AsCRD1 shares $38 \%, 36 \%$, and $31 \%$ identity (54\%, 50\%, and $48 \%$ similarity) with $A$. nidulans CrpA, C. albicans CaCRD1, and cucumber (Cucumis sativus) CsHMA5.2, respectively, while AsCCC2 shows $35 \%$ identity and $51 \%$ similarity with both the S. cerevisiae Ccc2 and A. thaliana AtHMA5. As further indicated in the Neighbor-joining tree (Supplementary Figure S2), AsCRD1
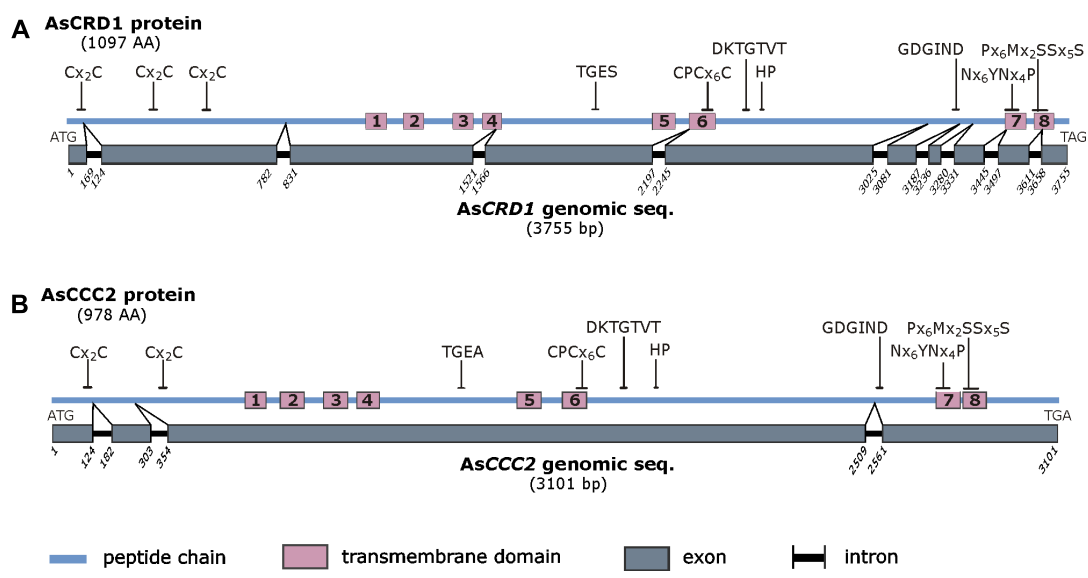

FIGURE 1 | Schematic representation of the predicted AsCRD1 protein (A) and AsCCC2 protein (B) and the corresponding genomic sequences. The characteristic amino acid sequence motifs are indicated and include $\mathrm{Cx}_{2} \mathrm{C}$ metal binding motif, sequence features characteristic of phosphatase domain (TGE[S/A]), aspartyl

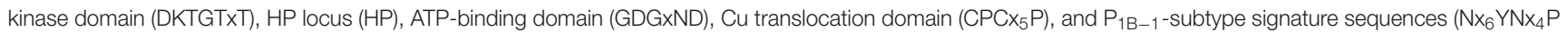

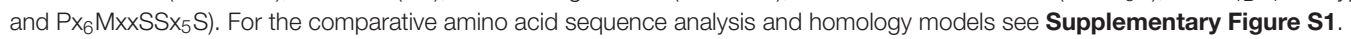


and AsCCC2 sort into two distinct clusters. The AsCRD1containing cluster comprised the characterized CaCRD1 and a clade of predicted agaricomycete $\mathrm{P}_{1 \mathrm{~B}-1}$-ATPases. The second cluster involved clearly separated clades of mammalian and plant $\mathrm{P}_{1 \mathrm{~B}-1}$-ATPases together with the AsCCC2-containing agaricomycete clade, which was more closely related to plant than to mammalian or yeast transporters. It is noteworthy that among the characterized transporters from Ascomycetes and Basidiomycetes, the closest relatives of AsCCC2 were $\mathrm{P}_{1 \mathrm{~B}-1^{-}}$ATPases from plant pathogens Botrytis cinerea (Saitoh et al., 2010) and Colletotrichum lindemuthianum (Parisot et al., 2002), and human pathogen Cryptococcus neoformans (Walton et al., 2005).

\section{Functional Expression of AsCRD1 and AsCCC2 in S. cerevisiae}

The homology to known fungal $\mathrm{P}_{1 \mathrm{~B}-1}$-ATPases suggested that

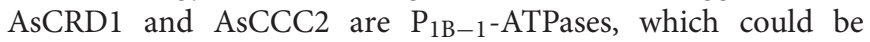
involved in metal tolerance and delivery of $\mathrm{Cu}$ to metalloproteins, respectively. In order to gain information regarding the function of AsCRD1 and AsCCC2 in handling $\mathrm{Cu}$ and $\mathrm{Ag}$, the corresponding coding sequences were constitutively expressed in mutant S. cerevisiae strains grown on agar media with or without metal supplements. To attest the importance of the DKTGTxT motif in which the conserved aspartyl is in P-ATPases, a target of phosphorylation/dephosphorylation during the transport reaction cycle, the corresponding mutant $\mathrm{AsCRD1} 1^{\mathrm{D} 742 \mathrm{~A}}$ and AsCCC2 $2^{\mathrm{D} 555 \mathrm{~A}}$ variants were constructed, in which the codons for aspartyl 742 (in AsCRD1) and aspartyl 555 (in AsCCC2) were changed to encode alanyl residues.

The $\mathrm{Cu}$ tolerance assays were conducted in the cup1 $\Delta$ strain carrying a deletion of its single-copy MT gene cup1, which renders the cells hypersensitive to $\mathrm{Cu}$. Heterologous expression in yeasts grown on SD medium containing 50 or $100 \mu \mathrm{M}$ $\mathrm{Cu}^{2+}$ revealed that only AsCRD1, but not AsCCC2, protected the yeasts form $\mathrm{Cu}$ toxicity (Figure 2A). The protective effect of AsCRD1 became weaker when the cells were subjected to $200 \mu \mathrm{M} \mathrm{Cu}^{2+}$ (Figure 2A). Considering that $\mathrm{Ag}^{+}$, particularly in respiratory conditions, acts as a potent inducer of oxidative stress (Mijnendonckx et al., 2013), and yeasts with defects in oxidative stress response proved useful in attributing Agdetoxification functions to heterologous proteins (Sácký et al., 2014; Migocka et al., 2015), the yap1s strain, deficient in a transcription factor upregulating genes involved in oxidative stress response (Rodrigues-Pousada et al., 2010), was used in Ag toxicity assays. As documented in Figure 2B, the yap1A cells grown on non-fermentable YPEG medium and expressing AsCRD1 grew much better in the presence of $5-30 \mu \mathrm{M} \mathrm{Ag}{ }^{+}$ than did the controls. The observation that the expression of AsCRD1 $1^{\mathrm{D} 742 \mathrm{~A}}$ did not confer increased resistance against either $\mathrm{Cu}$ (Figure 2A) or Ag (Figure 2B) suggested that the $\mathrm{Cu}$ - and Ag-tolerance phenotypes associated in the model yeasts with wild-type AsCRD1 were indeed due to the metal-transport ability of the encoded protein.

The apparent lack of the $\mathrm{Ag} / \mathrm{Cu}$ toxicity-related phenotype of AsCCC 2 in cup $1 \Delta$ and yap $1 \Delta$ yeasts was congruent with the expected function of AsCCC2 as the transporter involved in

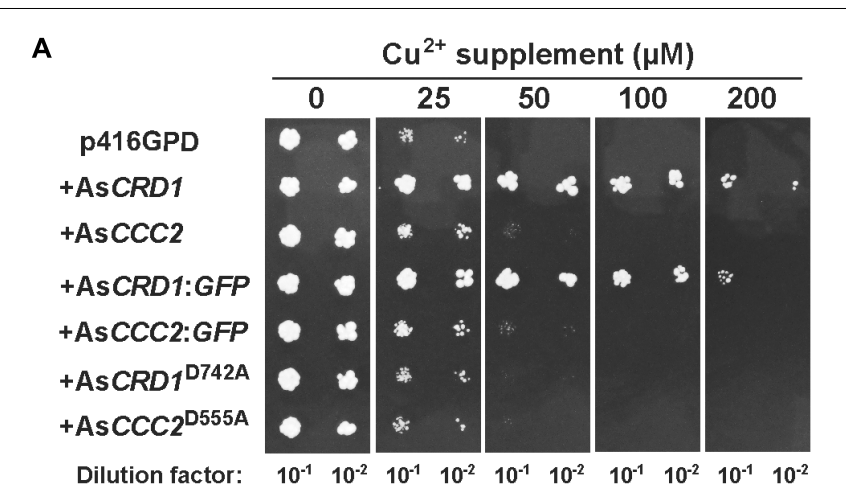

B

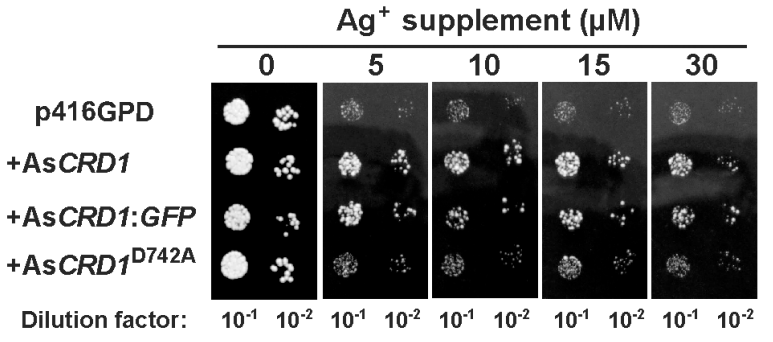

C

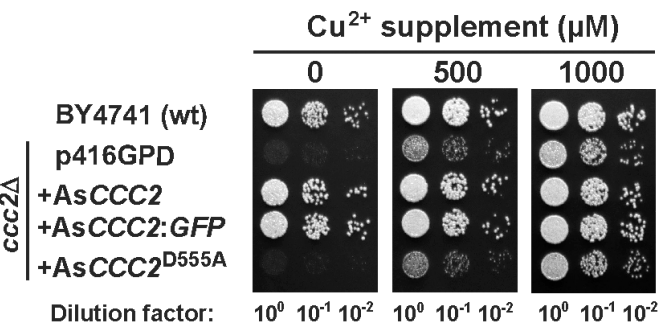

FIGURE 2 | Metal-related phenotypes of yeasts expressing AsCRD1 and AsCCC2 variants. (A) Cu tolerance and (B) Ag tolerance of the indicated transformants of Cu-hypersensitive cup $1 \Delta$ and Ag-sensitive yap $1 \Delta$ strains of S. cerevisiae, respectively. (C) Growth of the indicated transformants of $\operatorname{ccc} 2 \Delta$ strain under respiratory conditions. Spotted for growth were the diluted cultures of cells transformed with the empty p416GPD vector or with the same expression vector inserted with AsCRD1 or AsCCC2, their translational fusions with GFP, or mutant variants (AsCRD 1 ${ }^{\mathrm{D} 742 \mathrm{~A}}$,

AsCCC $2^{\mathrm{D} 555 \mathrm{~A}}$ ). Metal tolerance assays were performed using SD medium with or without indicated metal supplement and assays with $\operatorname{ccc} 2 \Delta$ strain were conducted on non-fermentable YPEG medium.

handling of physiological $\mathrm{Cu}$ inside the cell. The properties of AsCCC2 were thus further tested in the $\operatorname{ccc} 2 \Delta$ strain in which the absence of $\mathrm{Ccc} 2$ causes a severe growth defect on nonfermentable media because of the lack of sufficient mitochondrial iron (Fu et al., 1995; Yuan et al., 1997); note that high affinity iron uptake pathway in S. cerevisiae involves Fet1 permease that works together with $\mathrm{Cu}$-dependent, plasma membrane ferroxidase Fet3 that receives its $\mathrm{Cu}$ ions (supplied by $\mathrm{Ccc} 2$ ) in Golgi. The growth tests on YPEG medium revealed that AsCCC2 was able to fully complement the respiratory deficiency of the $\operatorname{ccc} 2 \Delta$ cells, whilst the control cells transformed with empty p416GPD and those expressing AsCCC2 $2^{\mathrm{D} 555 \mathrm{~A}}$ (and AsCRD1; not shown) failed to grow under the same conditions (Figure 2C). The 
controls, AsCRD1 (not shown), and AsCCC2 $2^{\text {D555A }}$ cells showed full growth on the YPEG medium supplemented with $1 \mathrm{mM}$ $\mathrm{Cu}^{2+}$, respectively.

\section{Targeting of AsCRD1 and AsCCC2 in S. cerevisiae}

Distinct phenotypes associated with AsCRD1 and AsCCC2 in yeasts suggested that the corresponding proteins localized to different membranes. To obtain information about the cellular localization of AsCRD1 and AsCCC2 using direct fluorescence microscopy, the proteins were translationally fused with GFP at their C-termini, and the recombinant AsCRD1:GFP and AsCCC2:GFP genes were expressed in $c u p 1 \Delta$ and $c c c 2 \Delta$ yeasts grown in SD medium. Complementation assays revealed that the phenotypes conferred by the fusions upon the yeasts were essentially the same as those observed with the corresponding transporters without GFP (Figure 2), thereby indicating that AsCRD1 and AsCCC2 tagged with GFP at their C-termini remained functional.

The microscopy of AsCRD1:GFP-expressing cup1 $\triangle$ yeasts revealed strong GFP fluorescence co-localizing exclusively with the tonoplast stained with the vacuole-specific fluorophore FM4-64 (Figure 3A). The expression of AsCCC2:GFP in the $\operatorname{ccc} 2 \Delta$ strain resulted in a strong, punctuated GFP signal in vesicular bodies within the cell (Figure 3B). The absence of GFP fluorescence from the perinuclear region attributable to ER may suggest that AsCCC2:GFP localized to Golgi rather than ER. The localization of GFP fluorescence in AsCRD1:GFPand AsCCC2:GFP-transformed yeasts was not affected by the presence of subtoxic concentrations of $\mathrm{Cu}$ or $\mathrm{Ag}$ or the length of culture period (not shown).

\section{Metal Responsiveness of AsCRD1 and AsCCC2 in A. strobiliformis}

Considering the AsCRD1-associated, metal tolerance-related phenotypes in the model yeasts and the typically induced expression of metal tolerance genes during metal overload, the transcription rates of the studied $\mathrm{P}_{1 \mathrm{~B}-1}$-ATPases genes were analyzed by using qRT-PCR, measuring mRNA levels in the mycelium of $A$. strobiliformis treated with 5 and $50 \mu \mathrm{M} \mathrm{Cu}^{2+}$, 5,20 , and $50 \mu \mathrm{M} \mathrm{Ag}^{+}$, or $5 \mu \mathrm{M} \mathrm{Cd}^{2+}$ for $24 \mathrm{~h}$. The $\mathrm{Cu}$ and $\mathrm{Ag}$ concentrations used in the 24-h exposures proved sublethal also in long-term exposures (Figure 4A), although the radial growth of mycelia was strongly reduced (by 70\%) in the presence of $50 \mu \mathrm{M}$ Ag. The mycelia always developed brown zones already at $5 \mu \mathrm{M}$ of any of the metals, presumably due to the induced production of stress-related melanin (Gostinčar et al., 2012).

As shown in Figure 4B, $24 \mathrm{~h}$ treatments of mycelia with $\mathrm{Ag}$ and $\mathrm{Cu}$ clearly elevated the expression of AsCRD1, but not AsCCC2, relative to the unexposed control. The average levels of AsCRD1 transcripts increased 4.5- and 8.7-fold in the presence of $5 \mu \mathrm{M} \mathrm{Ag}^{+}$and $\mathrm{Cu}^{2+}$, respectively, and they further nearly doubled when the concentration of the two metals was $50 \mu \mathrm{M}$. Neither AsCRD1 nor AsCCC2 showed significant response when the mycelia were treated with a $5 \mu \mathrm{M}$ concentration of $\mathrm{Cd}^{2+}$ (Figure 4B), which in A. strobiliformis induces the expression of

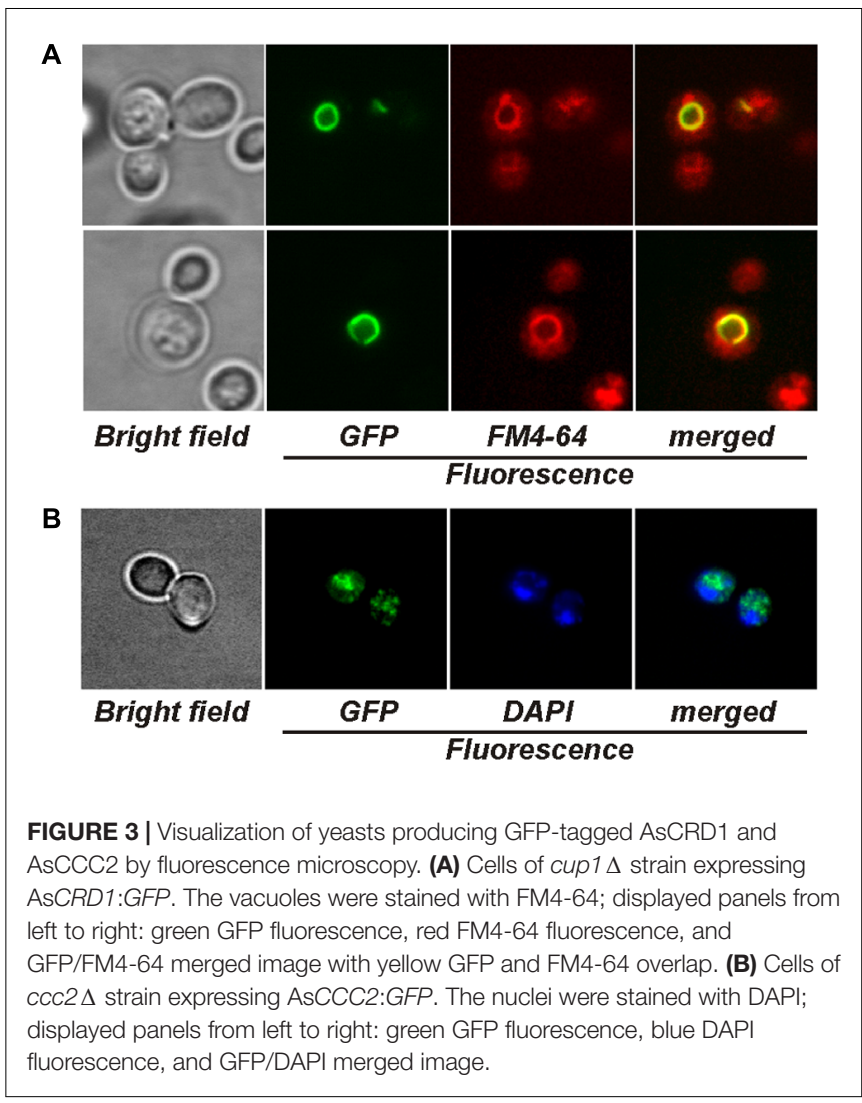

$\mathrm{Zn}^{2+} / \mathrm{Cd}^{2+}$-related MT gene AsMT3, but not $\mathrm{Cu}^{+} / \mathrm{Ag}^{+}$-related AsMT1s (Hložková et al., 2016).

\section{DISCUSSION}

Our previous studies revealed a certain overlap in the cellular biology of $\mathrm{Cu}$ and $\mathrm{Ag}$ in the EM, Ag-hyperaccumulating fungus A. strobiliformis - both metals can enter the cells via AsCTR2 and AsCTR3 transporters (Beneš et al., 2016) and intracellular Cu and $\mathrm{Ag}$ are sequestered in the cytoplasm through binding with AsMT1s (Hložková et al., 2016). It is worth noting that MTs have been considered principal in the sequestration of $\mathrm{Cu}$ or $\mathrm{Ag}$ in many EM fungi, including Pisolithus albus (Reddy et al., 2016), Laccaria bicolor (Reddy et al., 2014), Hebeloma mesophaeum (Sácký et al., 2014), Hebeloma cylindrosporum (Ramesh et al., 2009), Amanita submembranacea (Borovička et al., 2010), and Paxillus involutus (Bellion et al., 2007). The present study aimed to identify $\mathrm{P}_{1 \mathrm{~B}-1}$-ATPases of $A$. strobiliformis and inspect their potential role in the handling of intracellular $\mathrm{Cu}$ and $\mathrm{Ag}$ in this species. Our search of the sporocarp transcriptome suggested the presence of several putative $\mathrm{P}_{1 \mathrm{~B}}$-ATPases of which only two showed sequence features characteristic of the $\mathrm{P}_{1 \mathrm{~B}-1}$ subgroup.

Unlike for $\mathrm{Zn}$ or $\mathrm{Cd}$, information about the deposition of the excess of the accumulated $\mathrm{Cu}$ in fungal vacuoles is scarce. In Aspergillus niger (Fomina et al., 2007) and in arbuscular mycorrhizal Rhizophagus intraradices 


\section{A}

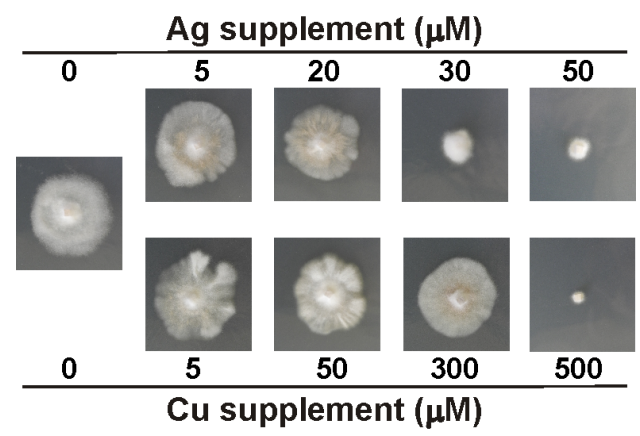

B

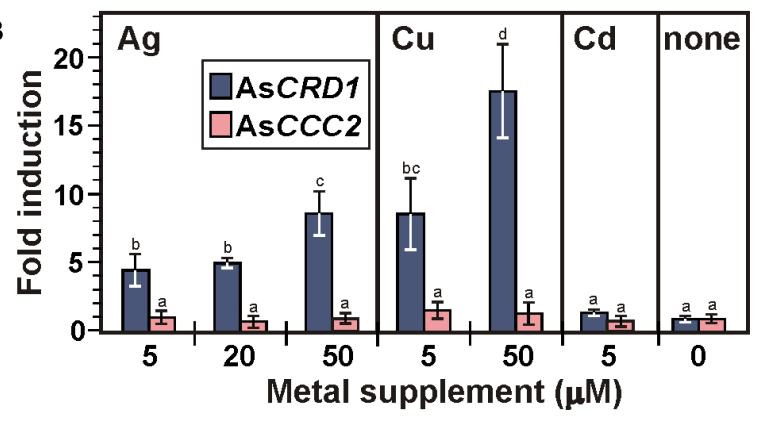

FIGURE 4 | Growth of $A$. strobiliformis and expression of AsCRD1 and AsCCC2 genes in the presence of metal ions as indicated. (A) Mycelia grown on $0.5 \times$ PD medium with or without metal supplement for 8 weeks (long-term exposure). (B) Relative transcript levels measured by qRT-PCR in mycelium incubated in liquid $0.5 \times$ PD medium for $24 \mathrm{~h}$ with or without (the controls) metal supplement (short term exposure). Expression of $\beta$-tubulin gene was used to calculate the relative expression and values plotted are an average of three biological replicates \pm standard deviation of the mean (different letters above the bars indicate significant differences as determined by ANOVA followed by Tukey's test, $p<0.05)$.

(González-Guerrero et al., 2008), the vacuolar sequestration of excess $\mathrm{Cu}$ was revealed by X-ray microanalyses, which further suggested the association of $\mathrm{Cu}$ with vacuolar polyphosphate in $A$. niger. The vacuole is an important organelle for $\mathrm{Cu}$ homeostasis in S. cerevisiae and the strains defective in vacuolar assembly are hypersensitive to $\mathrm{Cu}$ (Szczypka et al., 1997). While the transporters of the CTR family responsible for the mobilization of the vacuolar $\mathrm{Cu}$ back into the fungal cytoplasm are well characterized (e.g., Ctr2 in S. cerevisiae; Bleackley and MacGillivray, 2011), the Cu-specific, high-affinity transporters that can deliver $\mathrm{Cu}$ into the vacuoles remained elusive.

Besides the sequence features common in P-ATPases, in particular of the $\mathrm{P}_{1 \mathrm{~B}}$-subtype, several lines of experimental evidence implicate that AsCRD1 can act as a detoxification $\mathrm{P}_{1 \mathrm{~B}-1}$-ATPase that can transport $\mathrm{Cu}^{+}$and $\mathrm{Ag}^{+}$into vacuoles in A. strobiliformis. First, the expression of AsCRD1, but not AsCRD1 $1^{\mathrm{D} 742 \mathrm{~A}}$, protected the model yeasts from $\mathrm{Cu}$ and $\mathrm{Ag}$ toxicity. The observation that the replacement of aspartyl with alanyl in the DKTGTxT motif (to prevent the phosphorylation in AsCRD1 ${ }^{\mathrm{D} 742 \mathrm{~A}}$ from ATP) abolished the AsCRD1-associated phenotype in both cup1 $\Delta$ and yap1 1 yeast mutants further indicates that AsCRD1 can recognize both $\mathrm{Cu}$ and $\mathrm{Ag}$ for an active, ATP-dependent transport, and that it was the metal transport that increased the metal tolerance in the yeasts, not a mere immobilization of $\mathrm{Cu}^{+}$or $\mathrm{Ag}^{+}$through binding to cytoplasmic N-terminal metal binding motifs as it is the case, e.g., of $\mathrm{Cu}$-binding to the Cd-transporting PCA1 in S. cerevisiae (Adle et al., 2007). Second, the functional GFP-tagged AsCRD1 was targeted to the tonoplast in model yeasts. Although vacuolar $\mathrm{P}_{1 \mathrm{~B}-1}$-ATPases have not been described in fungi before, such localization is not without precedent. Recent studies in plants have identified the Cu-transporting S. vulgaris SvHMA5II (Li et al., 2017), and cucumber (Cucumis sativus) Cu- and also Agactivated CsHMA5.1 and CsHMA5.2 proteins (Migocka et al., 2015), as tonoplast-localizing $\mathrm{P}_{1 \mathrm{~B}-1}$-ATPases facilitating metal detoxification in root cells. Third, the observation that the expression of AsCRD1 was in A. strobiliformis effectively induced by $\mathrm{Cu}$ and $\mathrm{Ag}$ makes it reasonable to assume that AsCRD1 is involved in the cellular biology of both metals and the fungus raises the levels of AsCRD1 to handle excess intracellular $\mathrm{Cu}$ and $\mathrm{Ag}$. Considering that our previous metal speciation analyses using size exclusion chromatography revealed that the majority of the $\mathrm{Ag}$ and $\mathrm{Cu}$ accumulated in A. strobiliformis is stably bound in 6-kDa complexes with Ag- and $\mathrm{Cu}$-inducible, cytosolic AsMT1s (Osobová et al., 2011; Beneš et al., 2016; Hložková et al., 2016), one may then ask the question of what role AsCRD1 would have in metal detoxification. We propose that vacuolar storage could provide the second line of defense against high intracellular $\mathrm{Ag}$ and $\mathrm{Cu}$ levels, perhaps during a temporal deficiency of $\mathrm{Cu}^{+}$- and $\mathrm{Ag}^{+}$-binding AsMT1s, akin to the function of zincosome vesicles acting as transient stores of the excess accumulated $\mathrm{Zn}$ in S. cerevisiae (Devirgiliis et al., 2004). However, considering the plasma membrane localization of the closely related CaCRD1 in C. albicans (Riggle and Kumamoto, 2000; Weissman et al., 2000) and CrpA in A. nidulans (AntsotegiUskola et al., 2017), the possibility that AsCRD1 mislocalizes in $S$. cerevisiae and in A. strobiliformis acts as a transporter that exports the excess $\mathrm{Cu}$ and $\mathrm{Ag}$ out of the cells should not be excluded.

The predicted AsCCC2 and its homologs from Agaricomycetes appeared phylogenetically associated with the Ccc2 protein from the unicellular basidiomycete $C$. neoformans and to a lesser extent with $\mathrm{Ccc} 2 \mathrm{~s}$ from ascomycetes $B$. cinerea, C. lindemuthianum and $S$. cerevisiae. Congruent with this observation, AsCCC2 functionally complemented the CCC2 gene in $S$. cerevisiae $\operatorname{ccc} 2 \Delta$ that is unable to charge its multicopper oxidase Fet3 with $\mathrm{Cu}$ in Golgi to establish the Fet3-Ftr1-based iron uptake system (Bleackley and MacGillivray, 2011). The lack of the AsCCC2-associated phenotype resulting from the D-to-A substitution in the DKTGTxT motif of the encoded protein (in the $\operatorname{ccc} 2 \Delta$ cells expressing AsCCC2 ${ }^{\mathrm{D} 555 \mathrm{~A}}$ ), and the GFP fluorescence localizing to the intracellular punctuate bodies resembling Golgi in yeasts expressing AsCCC2:GFP provides further support to the notion that AsCCC2 can mediate active transport of $\mathrm{Cu}$ into the Golgi. In C. neoformans, $B$. cinerea, and C. lindemuthianum, the corresponding functional CCC2 gene appeared critical for the biosynthesis of melanin; the lack of CCC2 in these species lead to a disruption in the delivery of $\mathrm{Cu}$ to extracellular multicopper oxidases 
(laccases in particular) during their trafficking through Golgi (Parisot et al., 2002; Walton et al., 2005; Saitoh et al., 2010). Multiple copies of laccase genes have been predicted in both saprobic and EM species (Kohler et al., 2015); for example, the genomes of saprobic Amanita thiersii and EM Amanita muscaria contain 15 and 18 putative nonallelic laccase genes, respectively. Recent studies indicate that laccases expressed in EM fungi are, besides the pigmentation, involved in the sporocarp development or nutrient acquisition in extraradical mycelia (Courty et al., 2009; Kües and Rühl, 2011; Ellström et al., 2015; Shah et al., 2016). Considering this and the fact that Fet3-like ferroxidase genes have been found in most sequenced basidiomycetes, including Amanita species (Kües and Rühl, 2011; Kohler et al., 2015), it could be possible that $A$. strobiliformis benefits from AsCCC2 for both the Fe-uptake complex and laccase(s) assembly via $\mathrm{Cu}$ handling.

The results obtained in this study indicate that AsCRD1 and AsCCC2 belong to two separate protein clusters of the $\mathrm{P}_{1 \mathrm{~B}-1}$-ATPase subgroup. The collected data strongly suggest that AsCRD1 is in A. strobiliformis, like AsMT1s and AsCTRs, involved in the handling of both $\mathrm{Ag}$ and $\mathrm{Cu}$, specifically in supporting the detoxification of $\mathrm{Ag}$ and $\mathrm{Cu}$, which is, besides efficient transport, the prerequisite for (hyper)accumulation. Our data further indicate that AsCCC2, identified as another $\mathrm{P}_{1 \mathrm{~B}-1}$-ATPase of $A$. strobiliformis, is a functional homolog of yeast $\mathrm{Ccc} 2$, involved in the delivery of physiological $\mathrm{Cu}$ into organelles of endomembrane system for the biosynthesis of $\mathrm{Cu}$ dependent proteins. It is worth noting that BLASTp returned putative $\mathrm{P}_{1 \mathrm{~B}-1}$-type ATPases of Agaricomycetes species in which homologs of AsCRD1 and AsCCC2 were identified. These species belong to different orders (Supplementary Figure S2) of different lifestyles. It is thus tempting to speculate that the functional specialization and roles of $\mathrm{P}_{1 \mathrm{~B}-1}$-type ATPases, which we here discussed for AsCRD1 and AsCCC2, are widespread among Agaricomycetes.

\section{AUTHOR CONTRIBUTIONS}

VB conducted the experimental work and analyzed and interpreted data. TL and JS jointly contributed to the conception and design of the study, the bioinformatic analyses, and helped with the interpretation of data. PK was responsible for the concept and design of the work and the interpretation of the results, ensured the scientific issue was appropriately investigated, and wrote the manuscript. All of the authors assisted in writing

\section{REFERENCES}

Adle, D. J., Sinani, D., Kim, H., and Lee, J. (2007).A cadmium-transporting P1Btype ATPase in yeast Saccharomycescerevisiae. J. Biol. Chem. 282, 947-955. doi: 10.1074/jbc.M609535200

Altschul, S. F., Gish, W., Miller, W., Myers, E. W., and Lipman, D. J. (1990). Basic local alignment search tool. J. Mol. Biol. 215, 403-410. doi: 10.1016/S00222836(05)80360-2

Antsotegi-Uskola, M., Markina-Iñarrairaegui, A., and Ugalde, U. (2017). Copper resistance in Aspergillus nidulans relies on the PI-type ATPase CrpA, regulated the manuscript, discussed the results, and commented on the manuscript.

\section{FUNDING}

This work was supported by the Czech Science Foundation through grant no. 16-15065S. Publication fees of the work have been co-financed by the endowment from the Ministry of Education, Youth and Sports of Czechia for the institutional development plan at UCT Prague.

\section{ACKNOWLEDGMENTS}

We are grateful to Prof. Dennis J. Thiele (Duke University Medical Center) for the gift of DTY113 (cup1 $\Delta$ ) strain. We thank Dr. Jan Borovička (Institute of Geology and Nuclear Physic Institute, CAS) for the valuable discussions.

\section{SUPPLEMENTARY MATERIAL}

The Supplementary Material for this article can be found online at: https://www.frontiersin.org/articles/10.3389/fmicb. 2018.00747/full\#supplementary-material

FIGURE S1 | (A) Comparative sequence analysis of the predicted AsCRD1 and AsCCC2 proteins. Sequences were aligned by using ClustalW and the identical, conservative, and semiconservative residues were marked with asterisks, double dots, and single dots, respectively. The predicted transmembrane domains (TMD, numbered) are highlighted with light blue background and the characteristic sequence motifs are boxed in yellow (metal binding $\mathrm{CxxC}$ motif), green (CPCx ${ }_{6} \mathrm{P}$ in

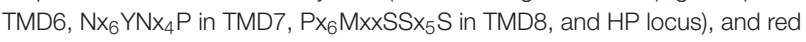
(DKTGTxT motif). The signal peptide predictions in AsCRD1 and AsCCC2 at CCTOP and Signal P 4.1 servers did not unveil any potential signal sequences. (B) 3D homology models of AsCRD1 and AsCCC2. The PDB entries used for the comparative modeling of AsCRD1 and AsCCC2 were 2EW9 (N-terminal domain of ATP7B, 23\% and 40\% identity, respectively) and 3J09 ( $\mathrm{P}_{1 \mathrm{~B}-1}$-ATPase CopA of Archaeoglobus fulgidus; $34 \%$ and $41 \%$ identity, respectively). The positions of characteristic sequence motifs are indicated with arrows.

FIGURE S2 | An unrooted, neighbor-joining-based tree of characterized and predicted $\mathrm{P}_{1 \mathrm{~B}-1}$-ATPases. Species name and UniProt accession numbers of functionally characterized ascomycete, plant and mammalian, and predicted Agaricomycetes $\mathrm{P}_{1 \mathrm{~B}-1}$-ATPases (30\% to $40 \%$ identical with AsCRD1 or AsCCC2; UniProt expect values of 0 to $10^{-97}$ ) are indicated. The tree was generated by MEGA version 6.0 after the sequence alignment by using ClustalW. Bootstrap values (\%; 1,000 replicates) are shown at nodes (values < $40 \%$ are omitted for clarity) and branch lengths are proportional to phylogenetic distances.

TABLE S1 | Primers used in this study.

by the transcription factor AceA. Front. Microbiol. 8:912. doi: 10.3389/fmicb. 2017.00912

Argüello, J. M., Eren, E., and González-Guerrero, M. (2007). The structure and function of heavy metal transport P-1B-ATPases. Biometals 20, 233-248. doi: 10.1007/s10534-006-9055-6

Bashir, K., Rasheed, S., Kobayashi, T., Seki, M., and Nishizawa, N. K. (2016). Regulating subcellular metal homeostasis: the key to crop improvement. Front. Plant Sci. 7:1192. doi: 10.3389/fpls.2016.01192

Bellion, M., Courbot, M., Jacob, C., Guinet, F., Blaudez, D., and Chalot, M. (2007). Metal induction of a Paxillus involutus metallothionein and its heterologous 
expression in Hebeloma cylindrosporum. New Phytol. 174, 151-158. doi: 10.1111/j.1469-8137.2007.01973.x

Beneš, V., Hložková, K., Matěnová, M., Borovička, J., and Kotrba, P. (2016). Accumulation of $\mathrm{Ag}$ and $\mathrm{Cu}$ in Amanita strobiliformis and characterization of its $\mathrm{Cu}$ and $\mathrm{Ag}$ uptake transporter genes AsCTR2 and AsCTR3. Biometals 29, 249-264. doi: 10.1007/s10534-016-9912-x

Bleackley, M. R., and MacGillivray, R. T. (2011). Transition metal homeostasis: from yeast to human disease. Biometals 24, 785-809. doi: 10.1007/s10534-0119451-4

Borovička, J., Kotrba, P., Gryndler, M., Mihaljevič, M., Řanda, Z., Rohovec, J., et al. (2010). Bioaccumulation of silver in ectomycorrhizal and saprobic macrofungi from pristine and polluted areas. Sci. Total Environ. 408, 2733-2744. doi: $10.1016 /$ j.scitotenv.2010.02.031

Borovička, J.,Řanda, Z., Jelínek, E., Kotrba, P., and Dunn, C. E. (2007). Hyperaccumulation of silver by Amanita strobiliformis and related species of the section Lepidella. Mycol. Res. 111, 1339-1344. doi: 10.1016/j.mycres.2007. 08.015

Colpaert, J. V., Wevers, J. H. L., Krznaric, E., and Adriaensen, K. (2011). How metal-tolerant ecotypes of ectomycorrhizal fungi protect plants from heavy metal pollution. Ann. For. Sci. 68, 17-24. doi: 10.1007/s13595-010-0 003-9

Courty, P. E., Hoegger, P. J., Kilaru, S., Kohler, A., Buée, M., Garbaye, J., et al. (2009). Phylogenetic analysis, genomic organization, and expression analysis of multi-copper oxidases in the ectomycorrhizal basidiomycete Laccaria bicolor. New Phytol. 182, 736-750. doi: 10.1111/j.1469-8137.2009.02774.x

Devirgiliis, C., Murgia, C., Danscher, G., and Perozzi, G. (2004). Exchangeable zinc ions transiently accumulate in a vesicular compartment in the yeast Saccharomyces cerevisiae. Biochem. Biophys. Res. Commun. 323, 58-64. doi: 10.1016/j.bbrc.2004.08.051

Dobson, L., Reményi, I., and Tusnády, G. E. (2015). CCTOP: A Consensus Constrained TOPology prediction web server. Nucleic Acids Res. 43, W408-W412. doi: 10.1093/nar/gkv451

Ellström, M., Shah, F., Johansson, T., Ahrén, D., Persson, P., and Tunlid, A. (2015). The carbon starvation response of the ectomycorrhizal fungus Paxillus involutus. FEMS Microbiol. Ecol. 91:fiv027. doi: 10.1093/femsec/fiv027

Falandysz, J., and Borovička, J. (2013). Macro and trace mineral constituents and radionuclides in mushrooms: health benefits and risks. Appl. Microbiol. Biotechnol. 97, 477-501. doi: 10.1007/s00253-012-4552-8

Fomina, M., Charnock, J., Bowen, A. D., and Gadd, G. M. (2007). X-ray absorption spectroscopy (XAS) of toxic metal mineral transformations by fungi. Environ. Microbiol. 9, 308-321. doi: 10.1111/j.1462-2920.2006.01139.x

$\mathrm{Fu}$, D., Beeler, T. J., and Dunn, T. M. (1995). Sequence, mapping and disruption of $\mathrm{CCC} 2$, a gene that cross-complements the $\mathrm{Ca}^{2+}$-sensitive phenotype of csg1 mutants and encodes a P-type ATPase belonging to the Cu2+-ATPase subfamily. Yeast 11, 283-292. doi: 10.1002/yea.320110310

Füzik, T., Ulbrich, P., and Ruml, T. (2014). Efficient mutagenesis independent of ligation (EMILI). J. Microbiol. Methods 106, 67-71. doi: 10.1016/j.mimet.2014. 08.003

Gadd, G. M., Rhee, Y. J., Stephenson, K., and Wei, Z. (2012). Geomycology: metals, actinides and biominerals. Environ. Microbiol. Rep. 4, 270-296. doi: 10.1111/j. 1758-2229.2011.00283.x

González-Guerrero, M., Melville, L. H., Ferrol, N., Lott, J. N. A., AzcónAguilar, C., and Peterson, R. L. (2008). Ultrastructural localization of heavy metals in the extraradical mycelium and spores of the arbuscular mycorrhizal fungus Glomus intraradices. Can. J. Microbiol. 54, 103-110. doi: 10.1139/w0 7-119

Gostinčar, C., Muggia, L., and Grube, M. (2012). Polyextremotolerant black fungi: oligotrophism, adaptive potential, and a link to lichen symbioses. Front. Microbiol. 3, 390. doi: 10.3389/fmicb.2012.00390

Hložková, K., Matìnová, M., Žáčková, P., Strnad, H., Hršelová, H., Hroudová, M., et al. (2016). Characterization of three distinct metallothionein genes of the Ag-hyperaccumulating ectomycorrhizal fungus Amanita strobiliformis. Fungal Biol. 120, 358-369. doi: 10.1016/j.funbio.2015.11.007

Kelley, L. A., Mezulis, S., Yates, C. M., Wass, M. N., and Sternberg, M. J. (2015). The Phyre2 web portal for protein modeling, prediction and analysis. Nat. Protoc. 10, 845-858. doi: 10.1038/nprot.2015.053

Kohler, A., Kuo, A., Nagy, L. G., Morin, E., Barry, K. W., Buscot, F., et al. (2015). Convergent losses of decay mechanisms and rapid turnover of symbiosis genes in mycorrhizal mutualists. Nat. Genet. 47, 410-415. doi: 10.1038/ng. 3223

Kües, U., and Rühl, M. (2011). Multiple multi-copper oxidase gene families in basidiomycetes - what for? Curr. Genomics 12, 72-94. doi: 10.2174/ 138920211795564377

La Fontaine, S., and Mercer, J. F. B. (2007). Trafficking of the copper-ATPases, ATP7A and ATP7B: Role in copper homeostasis. Arch. Biochem. Biophys. 463, 149-167. doi: 10.1016/j.abb.2007.04.021

Li, Y., Iqbal, M., Zhang, Q., Spelt, C., Bliek, M., Hakvoort, H. W. J., et al. (2017). Two Silene vulgaris copper transporters residing in different cellular compartments confer copper hypertolerance by distinct mechanisms when expressed in Arabidopsis thaliana. New Phytol. 215, 1102-1114. doi: 10.1111/ nph. 14647

Livak, K. J., and Schmittgen, T. D. (2001). Analysis of relative gene expression data using real-time quantitative PCR and the $2 \Delta \Delta \mathrm{C}(\mathrm{T})$ method. Methods 25 , 402-408. doi: 10.1006/meth.2001.1262

Migocka, M., Posyniak, E., Maciaszczyk-Dziubinska, E., Papierniak, A., and Kosieradzaka, A. (2015). Functional and biochemical characterization of cucumber genes encoding two copper ATPases CsHMA5.1 and CsHMA5.2. J. Biol. Chem. 290, 15717-15729. doi: 10.1074/jbc.M114. 618355

Mijnendonckx, K., Leys, N., Mahillon, J., Silver, S., and Van Houdt, R. (2013). Antimicrobial silver: uses, toxicity and potential for resistance. Biometals 26, 609-621. doi: 10.1007/s10534-013-9645-z

Mumberg, D., Müller, R., and Funk, M. (1995). Yeast vectors for the controlled expression of heterologous proteins in different genetic backgrounds. Gene 156, 119-122. doi: 10.1016/0378-1119(95)00037-7

Nevitt, T., Öhrvik, H., and Thiele, D. J. (2012). Charting the travels of copper in eukaryotes from yeast to mammals. Biochim. Biophys. Acta Mol. Cell Res. 1823, 1580-1593. doi: 10.1016/j.bbamcr.2012.02.011

Osobová, M., Urban, V., Jedelský, P. L., Borovička, J., Gryndler, M., Ruml, T., et al. (2011). Three metallothionein isoforms and sequestration of intracellular silver in the hyperaccumulator Amanita strobiliformis. New Phytol. 190, 916-926. doi: 10.1111/j.1469-8137.2010.03634.x

Palmgren, M. G., and Nissen, P. (2011). P-Type ATPases. Annu. Rev. Biophys. 40, 243-266. doi: 10.1146/annurev.biophys.093008.131331

Parisot, D., Dufresne, M., Veneault, C., Laugé, R., and Langin, T. (2002). clap1, a gene encoding a copper-transporting ATPase involved in the process of infection by the phytopathogenic fungus Colletotrichum lindemuthianum. Mol. Genet. Genomics 268, 139-151. doi: 10.1007/s00438-0020744-8

Pettersen, E. F., Goddard, T. D., Huang, C. C., Couch, G. S., Greenblatt, D. M., Meng, E. C., et al. (2004). UCSF Chimera - a visualization system for exploratory research and analysis. J. Comput. Chem. 25, 1605-1612. doi: 10.1002/jcc. 20084

Ramesh, G., Podila, G. K., Gay, G., Marmeisse, R., and Reddy, M. S. (2009). Different patterns of regulation for the copper and cadmium metallothioneins of the ectomycorrhizal fungus Hebeloma cylindrosporum. Appl. Environ. Microbiol. 75, 2266-2274. doi: 10.1128/AEM.02142-08

Reddy, M. S., Kour, M., Aggarwal, S., Ahuja, S., Marmeisse, R., and FraissinetTachet, L. (2016). Metal induction of a Pisolithus albus metallothionein and its potential involvement in heavy metal tolerance during mycorrhizal symbiosis. Environ. Microbiol. 18, 2446-2454. doi: 10.1111/1462-2920.13149

Reddy, M. S., Prasanna, L., Marmeisse, R., and Fraissinet-Tachet, L. (2014). Differential expression of metallothioneins in response to heavy metals and their involvement in metal tolerance in the symbiotic basidiomycete Laccaria bicolor. Microbiology 160, 2235-2242. doi: 10.1099/mic.0.080 218-0

Riggle, P. J., and Kumamoto, C. A. (2000). Role of a Candida albicans P1type ATPase in resistance to copper and silver ion toxicity. J. Bacteriol. 182, 4899-4905. doi: 10.1128/JB.182.17.4899-4905.2000

Rodrigues-Pousada, C., Menezes, R. A., and Pimentel, C. (2010). The Yap family and its role in stress response. Yeast 27, 245-258. doi: 10.1002/yea. 1752

Sácký, J., Leonhardt, T., Borovička, J., Gryndler, M., Briksí, A., and Kotrba, P. (2014). Intracellular sequestration of zinc, cadmium and silver in Hebeloma mesophaeum and characterization of its metallothionein genes. Fungal Genet. Biol. 64, 3-14. doi: 10.1016/j.fgb.2014.03.003 
Saitoh, Y., Izumitsu, K., Morita, A., and Tanaka, C. (2010). A copper-transporting ATPase BcCCC2 is necessary for pathogenicity of Botrytis cinerea. Mol. Genet. Genomics 284, 33-43. doi: 10.1007/s00438-010-0545-4

Shah, F., Nicolás, C., Bentzer, J., Ellström, M., Smits, M., Rineau, F., et al. (2016). Ectomycorrhizal fungi decompose soil organic matter using oxidative mechanisms adapted from saprotrophic ancestors. New Phytol. 209, 1705-1719. doi: $10.1111 /$ nph. 13722

Smith, A. T., Smith, K. P., and Rosenzweig, A. C. (2014). Diversity of the metaltransporting P1B-type ATPases. J. Biol. Inorg. Chem. 19, 947-960. doi: 10.1007/ s00775-014-1129-2

Szczypka, M. S., Zhu, Z., Silar, P., and Thiele, D. J. (1997). Saccharomyces cerevisiae mutants altered in vacuole function are defective in copper detoxification and iron-responsive gene transcription. Yeast 13, 1423-1435. doi: 10.1002/(SICI) 1097-0061(199712)13:15<1423::AID-YEA190>3.0.CO;2-C

Tamai, K. T., Gralla, E. B., Ellerby, L. M., Valentine, J. S., and Thiele, D. J. (1993). Yeast and mammalian metallothioneins functionally substitute for yeast copper-zinc superoxide dismutase. Proc. Natl. Acad. Sci. U. S. A. 90, 8013-8017. doi: 10.1073/pnas.90.17.8013

Tamura, K., Stecher, G., Peterson, D., Filipski, A., and Kumar, S. (2013). MEGA6: molecular evolutionary genetics analysis version 6.0. Mol. Biol. Evol. 30, 2725-2729. doi: 10.1093/molbev/mst197

Thompson, J. D., Higgins, D. G., and Gibson, T. J. (1994). CLUSTAL W: Improving the sensitivity of progressive multiple sequence alignment through sequence weighting, position-specific gap penalties and weight matrix choice. Nucleic Acids Res. 22, 4673-4680. doi: 10.1093/nar/22.22.4673
Walton, F. J., Idnurm, A., and Heitman, J. (2005). Novel gene functions required for melanization of the human pathogen Cryptococcus neoformans. Mol. Microbiol. 57, 1381-1396. doi: 10.1111/j.1365-2958.2005.04779.x

Webb, B., and Sali, A. (2014). Comparative protein structure modeling using MODELLER. Curr. Protoc. Bioinformatics 47, 5.6.1-5.6.32. doi: 10.1002/ 0471250953.bi0506s47

Weissman, Z., Berdicevsky, I., Cavari, B. Z., and Kornitzer, D. (2000). The high copper tolerance of Candida albicans is mediated by a P-type ATPase. Proc. Natl. Acad. Sci. U.S.A. 97, 3520-3525. doi: 10.1073/pnas.97.7.3520

Yuan, D. S., Dancis, A., and Klausner, R. D. (1997). Restriction to copper transport in Saccharomyces cerevisiae to a late Golgi or post-Golgi compartments in the secretory pathway. J. Biol. Chem. 272, 25787-25793. doi: 10.1074/jbc.272.41. 25787

Conflict of Interest Statement: The authors declare that the research was conducted in the absence of any commercial or financial relationships that could be construed as a potential conflict of interest.

Copyright (c) 2018 Beneš, Leonhardt, Sácký and Kotrba. This is an open-access article distributed under the terms of the Creative Commons Attribution License (CC BY). The use, distribution or reproduction in other forums is permitted, provided the original author(s) and the copyright owner are credited and that the original publication in this journal is cited, in accordance with accepted academic practice. No use, distribution or reproduction is permitted which does not comply with these terms. 